\title{
A Bentall Is Not a Bentall Is Not a Bentall: The Evolution of Aortic Root Surgery
}

\author{
Scott Maddalo, BA*, Jared Beller, BSE, Abe DeAnda, MD, FACS \\ New York University Langone Medical Center, New York, New York, USA
}

\begin{abstract}
Background: Aortic root pathology had been a known entity with a progressive and catastrophic course, long before the methods to surgically address them were first developed. Once reliable cardiopulmonary bypass was established, surgeons were able to pioneer new operative techniques, and in the half-century to follow, countless modifications and refinements have provided today's surgeons with the surgical approaches that are currently at their disposal. History: Denton Cooley and Michael De Bakey reported the first successful surgical intervention for aneurysms involving the ascending aorta in 1956. Nearly a decade later, Hugh Bentall described his modification, and provided a name that would leave a lasting mark on aneurysmal surgery. In the decades to follow, numerous innovative surgeons improved on these original procedures to allow for a more reliable and consistent operation. Further, Tirone David and Sir Magdi Yacoub each described their methods to repair the aortic root while preserving the valve, thus providing their patients with freedom from a prosthetic or mechanical valve and improved quality of life. Conclusions: The development of surgical techniques required to successfully care for patients with pathology of the aortic root has evolved considerably since Cooley and De Bakey's original report. Although it is common to hear aortic root replacement referred to as a "Bentall," the methods currently employed have gone through considerable evolution, such that the techniques of today should not be referred to as a Bentall.

Copyright @ 2014 Science International Corp.
\end{abstract}

\section{Key Words}

Aortic root - Bentall procedure - Cabrol procedure • Valve-sparing surgery

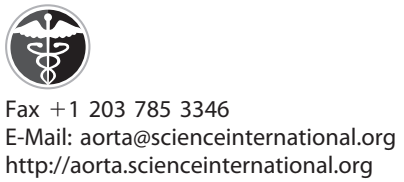

\section{(c) 2014 Aorta.}

Published by Science International Corp. ISSN 2325-4637

Accessible online at:

http://aorta.scienceinternational.org

\section{Introduction}

Aortic root pathology is often discovered incidentally after imaging is performed in patients for unrelated reasons. The most common indications for surgery of the aortic root are dilatation or aneurysm that disrupts the precise hemodynamic environment unique to the root (producing aortic insufficiency) and/or increases the risk of rupture or dissection. In the past, operating on the aortic root was reserved only for catastrophic circumstances. Current surgical repair of aneurysms affecting the aortic root and ascending aorta involves resection of the pathologic section and insertion of a graft. Recent innovations include aortic valve-sparing techniques, which provide patients with increased quality of life due to freedom from anticoagulation therapy, and increased longevity of the valve (compared to tissue valves). In instances where there is also concurrent aortic insufficiency or aortic cusp pathology, a composite valvegraft (either bioprosthetic or mechanical) may be used if the valve cannot be repaired. The purpose of this review is to focus on the historical aspects of aortic root surgery and to illustrate the evolution in operative technique.

\section{Perspective and Evolving Indications}

Aneurysms of the ascending aorta had been a well known entity prior to the first reports of their successful surgical management. There was little question as

\footnotetext{
*Corresponding author:

Scott Maddalo

NYU-Langone Medical Center

New York, New York 10016, USA

Tel: +1 212263 7300, Fax: +1 212263 3842, E-Mail: sm3526@nyu.edu
} 
to the progressive and fatal course, particularly in patients with Marfan syndrome or other connective tissue disorders. Although the majority of patients with isolated aneurysms remained asymptomatic, the risk for catastrophic consequences was known to increase as the size of the aneurysm grew. Despite the known natural history, little could be done to mitigate the risks with medications or to offer a curative surgical option. The surgical techniques currently employed developed out of a stepwise progression that began with the foundational challenges of overcoming cerebral anoxia and organ malperfusion, specifically the development of the cardiopulmonary bypass machine and the safe arrest of the heart. Over decades these techniques evolved, with surgeons seeking to recreate or maintain the intrinsic anatomical structure and function of the aortic root, most recently with the advent of valve-sparing procedures. Creativity, out of necessity, drove the innovations of the 20th century and enabled aortic root surgery to become reproducible, albeit potentially technically challenging, as the procedure remains today.

Prior to the 1970s, aortic root surgery was predominately performed in the setting of acute aortic catastrophe, on largely unstable, critically ill patients. These experiences with poor surgical candidates demonstrated an exceedingly high mortality. The innovative proof of concept that Hugh Bentall described in 1968, and the subsequent long-term track record that would follow, encouraged programs to begin prophylactic surgery, thereby reducing the risk of rupture and dissection, as well as offering a consistent, reproducible surgical outcome that could provide hope to those afflicted with this pathology. Bentall's work would not have been possible without the successes and failures that preceded him, nor would aortic root surgery be what it is today without the modifications by those that followed.

\section{Functional Anatomy}

The aortic root is the complex anatomical section that lies between the outlet of the left ventricle and the ascending aorta. Two virtual rings form the boundaries of this space. Proximally, the basal ring is defined by the aortic valve annulus. Distally, the sinotubular junction is marked by the superior limit of the valve cusp attachments. In addition to these anatom-

Maddalo, S. et al. ical landmarks, a critical component of valve physiology arises from the geometric relationships between the sinotubular junction and the basal ring. This region forms the sinuses of Valsalva, which serve to optimize cusp-loading, improve transvalvular hemodynamics, and minimize turbulence throughout the cardiac cycle [1]. In recent years, a more precise understanding of the fluid dynamics that arise from sinus geometry has developed [2]. This knowledge has the potential to guide prosthetic valve design and surgical repair, with the goals of minimizing cusp fatigue and stress, much like the native sinuses. Further, torsion within the aortic root as a result of helical blood flow functions to dissipate shear strains created during left ventricular contraction. A final anatomic consideration is the asymmetry among the three aortic cusps. The noncoronary cusp is the largest of the three and its basal attachment is to fibrous tissue lying in close proximity to the anterior leaflet of the mitral valve. The basal attachments of the left and right cusps are muscular, and because of this, the anterior section of the basal ring is more resistant to dilation.

\section{Surgical Technique}

\section{Initial Reports through the 1960s}

Denton Cooley and Michael De Bakey reported the first successful replacement of a fusiform ascending aneurysm in 1956 [3]. Prior to their experience, the means to correct aneurysms in this anatomical location had been limited to narrow-necked saccular aneurysms [4]. These could be corrected with tangential excision and aortorrhaphy. Reliable cardiopulmonary bypass had yet to be consistently performed, and even a brief interruption of aortic flow proximal to the aortic arch meant disastrous neurologic consequences. Cooley and De Bakey's report of the initial introduction of cardiopulmonary bypass to aortic aneurysm surgery was an incredible leap forward that allowed the surgeon to temporarily halt aortic flow without the compromise in systemic perfusion that would result in the absence of circulatory support. With the aid of cardiopulmonary bypass, surgeons now had the time and surgical exposure necessary to excise the defect and suture in place a homograft before restoring normal cardiac function.

In the years that followed, the surgical group at University of Oregon Medical School was at work cre- 
ating and redesigning mechanical ball-valve aortic prostheses [5]. They first performed implantation of their aortic ball-valve prosthesis in the fall of 1961 . Following that initial surgery, they worked through several iterations of their prototype, in order to achieve improved results. Their progression began with a three-pronged cage made from a cobalt-based alloy and a sewing margin consisting of a silicone ring coated with a double layer of Teflon cloth. Unfortunately, they observed an unacceptable rate of thromboembolic events in their early series. These sobering results encouraged them to progressively reduce the amount of exposed alloy, while modifying their material selection. By the end of the 1960s, they had altered their model by shortening and completely covering the cage with Dacron $^{\circledR}$, while using a highly polished, electron-beam welded ball [6].

Throughout the late 1950s and into the 1960s, others replicated procedures similar to the one that Cooley and De Bakey first described [7,8]. With the surgical experience of today, many of the attempted modifications may seem radical, but in the context of their day, creativity was the only option. Initially, ideas like bicuspidization of the valve through excision of the noncoronary cusp seemed promising, as it created a competent valve [9-11]. However, despite creative attempts such as this, no lasting innovation was developed until 1964, when Myron Wheat reported his team's efforts to replace the entire ascending aorta [12]. Although the procedure performed may not have involved the entire aorta as the title laid claim, its legacy was secured as a description of how to handle pathology extending proximal to the coronary ostia. The patient they describe suffered from a syphilitic aneurysm beginning at the aortic annulus and extending $11 \mathrm{~cm}$ to a point "several centimeters before the origin of the innominate artery [12], p.718." Their approach to the displaced coronary ostia was to resect the aorta $1.5-2 \mathrm{~cm}$ proximal to this level, while leaving a tongue of tissue surrounding the two coronary takeoffs. In this way, they maintained the integrity of the ostia and ensured the sutures were far enough from the coronary arteries to minimize the risk of thrombosis. Wheat modestly deflected credit and claimed that previously developed techniques "had merely awaited the appropriate patient [12], p.717." The next step in root revision had occurred. Surgeons now had the means to extend the excision beyond the level of the coronary ostia and avoided the need to reimplant the coronaries.

In 1966, Cooley published what had been his team's 10-year experience with aortic root and ascending aortic surgery [13]. At this early stage in the development of root surgery, they highlighted the fact that no single method of reconstruction was ideal, and that the patient's specific anatomy dictated which was the most appropriate method. This prescient view still holds true today, underscoring the importance of an individualized approach with the multiple surgical procedures now at our disposal. Further, at their point in the technical development, they credited the finely woven nonporous Dacron ${ }^{\circledR}$ graft with minimizing the hemorrhagic complications that arose as a result of the routine heparinization needed for cardiopulmonary bypass.

While others continued to work tirelessly, recreating and extending aortic repair, the group at Oregon, including Drs. Herr and Starr, were diligently at work devising mechanical valves that would eventually be used for Bentall's historic procedure [5,6]. In 1968, they published their ongoing clinical experience and engineering progress [6]. Even at this early point in the evolution of aortic root surgery, bold predictions about future progress were envisioned by Starr. In response to commentary on their article, he closed with his belief that they were already "approaching a time when consideration of earlier surgery will be possible [6], p.218." Although they were not yet ready to encourage prophylactic surgery, they felt that if their "experience [were to] continue along the lines that it has taken in the last few years, it may well be possible to do so in the near future [6], p.219."

At the time of Bentall and De Bono's classic report, a successful approach to proximal aortic pathology using cardiopulmonary bypass had existed for over a decade [14]. There is no doubt that their ingenuity to use a composite valve-graft prosthesis was a major step in the progression of aortic root surgery, and the composite valve-graft, whether using a mechanical (as originally done) or tissue valve, is still considered the gold standard today. In addition to the introduction of a composite valve-graft, the side-to-side anastomosis of the coronaries to the aortic prosthesis added to the legacy of the procedure. Although these two developments were crucial in the trajectory of the field, the authors fail to recognize some of the important steps that led to the possibility of such a technical advance- 

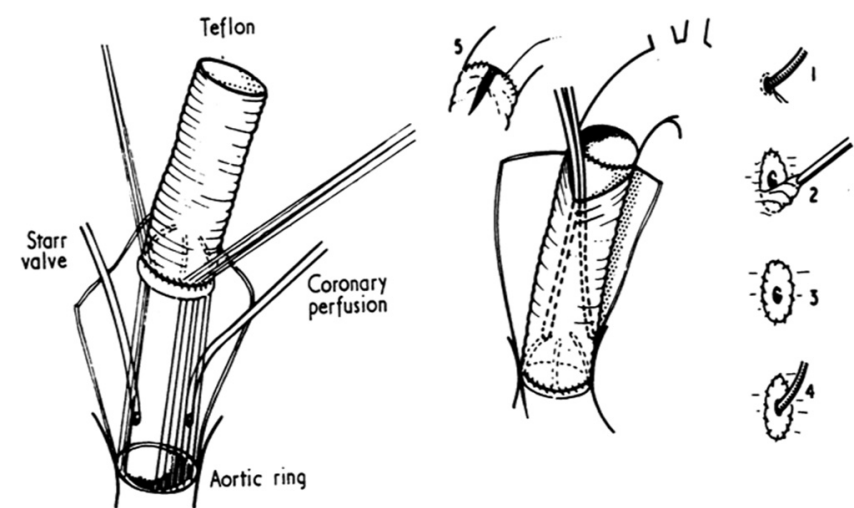

Figure 1. Classic drawing of Bentall's original root replacement. Figure reprinted with permission from Bentall et al. [14].

ment. Notably, they credit Cooley with the development of a combination valve prosthesis and aortic graft replacement, without mention of the work of Wheat. Despite this, their innovation secured a lasting name within aortic root repair. The early results of subsequent procedures were complicated by the tenuous anastomosis resulting from implantation of the coronaries into the graft with the inclusion technique. Further, pseudoaneurysm formation at the coronary anastomoses grew to be a well known concern following these original methods. The solution to the limitation in proximal excision created a new challenge, one that would fuel the next era of innovation seeking to improve on this technically challenging and often unpredictable procedure.

\section{Beyond a Classic Bentall: The Modifications Necessary} for a Reliable Procedure

The specific anatomic-pathologic changes seen in the aortic root are not consistent from patient to patient. This is particularly evident when considering the relationship of the coronary ostia to surrounding structures. Commonly, the dilative and degenerative process displaces the ostia to such an extent that direct anastomosis to the graft is facilitated: such was the case in Bentall's original procedure (Fig. 1). However, as the frequency of these operations grew from isolated case reports to larger series, it became evident that there were individuals in whom the restricted mobility of the ostia precluded an uncomplicated anastomosis. In the subset of patients with nondisplacement of the supra-annular segment, an alternative means of anastomosis needed to be devised.
Interposition of a conduit that could serve as an extension from the neoaorta to coronary artery was needed, but the ideal choice of material and specific method had yet to be established. In the mid 1970s, reports began to arise in which such attempts were made, but with inconsistent success. Blanco et al. [15] reported a promising approach, first unsuccessfully, but later with a positive result. In the first patient, both Dacron $^{\circledast}$ and then later a saphenous vein graft were used. Initially, Dacron ${ }^{\circledast}$ was selected, but poorly visualized and inaccessible hemorrhage from the anastomosis site forced them to reinstitute bypass, take down the graft, and make a second attempt to save the patient using vein grafts. The second attempt formed a hemostatic seal and allowed the patient to be weaned off bypass. Unfortunately, the patient died hours after the surgery due to uncontrollable arrhythmias, presumably from prolonged operative time. Despite the outcome of this initial attempt, they were encouraged to recreate this approach and did so successfully in subsequent operations. They praised the interposition of vein segments as it was felt to allow for a more tension-free anastomosis, provide a means for constant perfusion of the arterial tree during operation, and, most importantly, allowed the surgeon to assess the suture lines for potential sites of bleeding prior to removal of the cross clamp. They believed this alteration held the key to consistent reproducibility, essential for any lasting operative technique.

Though some surgeons believed a conduit would be the answer to improving reliability, others felt this added step should only be instituted as needed. In 1976, nearly a decade after Bentall's original description of his method, Zubiate and Kay [16] described their experiences correcting aneurysmal dilation of the ascending aorta. In 6 of the 41 patients they operated on, either the friability of the tissue or undue tension placed when creating the anastomosis forced them to entertain use of a saphenous vein conduit. Rather than direct end-to-end anastomosis from the coronary ostia, as had been attempted before, they elected a more distal section of the main coronary trunks for the distal anastomosis. In this manner, they sutured closed the coronary ostia, and then performed an end-to-side anastomosis onto the corresponding coronary artery.

Two years later, Cabrol described what would serve as the foundation for a series of modifications and alterations [17]. Unique to his approach was a single, 8 


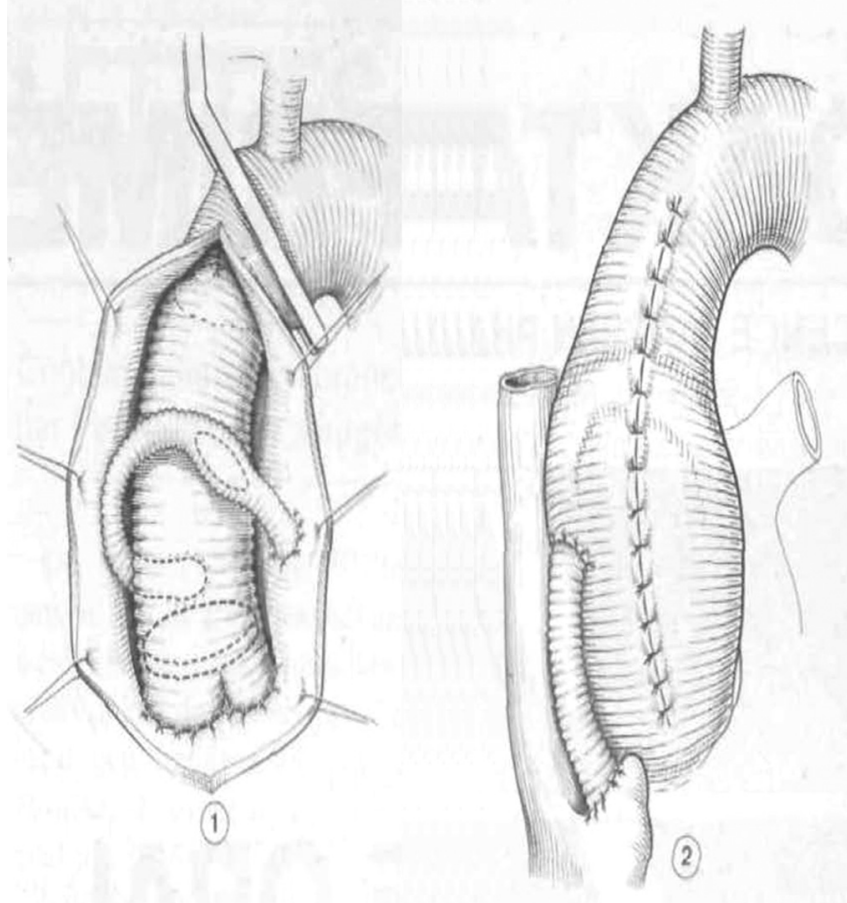

Figure 2. Drawing of Cabrol's root replacement technique. Figure reprinted with permission from Cabrol et al. [17].

$\mathrm{mm}$ Dacron ${ }^{\oplus}$ tube that functioned to supply the entire coronary circulation. In his operative technique, Cabrol first began with an end-to-end anastomosis between the left coronary orifice and the conduit (Fig. 2). He then shifted his attention to the completion of the aortic revision and, following completion of this component, returned to the coronary system. The opposite end of the single Dacron ${ }^{\circledR}$ conduit was anastomosed in an end-to-end fashion to the right coronary ostia. Finally, the single coronary conduit was made continuous with the aortic graft via a single side-toside anastomosis. Once the anastomoses were completed and adequate hemodynamics confirmed, the aneurysmal wall was closed over the revision, and a $1.5 \mathrm{~cm}$ fistula was created to the right atrial appendage. This was believed to be important in preventing tense hematoma formation, while minimizing postoperative blood loss by returning it to the circulation. Despite these creative solutions, Cabrol's operations were not without their unique complications, which would only become apparent through further experience.

In the years to follow, modifications to Cabrol's original procedure were described. In addition to Da- cron $^{\circledR}$ and saphenous vein conduits, Piehler and Pluth [18] made use of a beveled Gore-Tex ${ }^{\circledR}$ interposition graft. They stressed the importance of restricting the length of this conduit, and recommended against using segments in excess of $15-20 \mathrm{~mm}$. The particular case presented in their report featured asymmetric pathology of the coronary ostia, a presentation not uncommon in their practice. While the left coronary required a conduit due to insufficient displacement for direct anastomosis, the mobility of the right coronary permitted direct connection to the aortic graft via an inclusion technique. As additional operative techniques were added to the surgeon's armamentarium, the hybrid approach they described further affirmed the importance of decisions that suit a patient's individual anatomy.

In 1986, Cabrol reported on the outcomes several years following the operative technique he initially described in 1978 [19]. At the time, this was one of the first large cohort studies with promising long-term results, in some cases, up to eight years. Cabrol reported finding no pseudoaneurysms, a complication that was often seen with the classic Bentall procedure [20]. However, only $25 \%$ of patients were followed up with angiographic studies. What became apparent from later, larger, longer study periods were the complications owing to the distal aortic anastomosis. In the radiologic literature at the time, false aneurysm formation at this point was evident in up to $20 \%$ of patients within a few years [19]. Further, in Cabrol's cohort of 100 patients, four suffered from late dissections originating from this very site.

There were clearly differences in opinion as to the ideal modifications to Bentall's procedure that would make it an increasingly reproducible and safe procedure. This is highlighted by D. Craig Miller's comments that although Cabrol's approach is ingenious, it may be "a solution in search of a problem [19], p.24". His concern referred to adding unnecessary complexity to a procedure that is not always required. In his practice, patients who had nondisplaced coronaries with restricted mobility were ideally suited for a procedure akin to the one described classically by Wheat. This algorithm served as a means for Miller to avoid using conduits and encountering the complications inherent to this addition.

A final evolution that became increasingly prevalent during this era was best illustrated by Kouchoukos' description of his modifications throughout a 
series of 168 patients that he reported in 1991 [21]. Prior to 1981, an inclusion/wrap technique, in which the intrinsic aorta enclosed the graft for hemostatic purposes, was used. This was the generally accepted standard, but the risk of tense hematoma formation remained. As Cabrol demonstrated, a solution to this was the introduction of an iatrogenic fistula from the periprosthetic space draining to the right atrium [17]. He was confident that this communication would close spontaneously following the resolution of the coagulopathy after surgery and, if not, it would prove to be hemodynamically insignificant. In the years to follow, a number of reports of late complications owing to this connection were published in the literature $[22,23]$. Rather than drain the space, a method to decrease the permeability of the graft would achieve the same end. Kouchoukos began preclotting the Dacron $^{\circledast}$ graft with albumin, and this indeed improved hemostasis. Kouchoukos was also instrumental in popularizing an alternative means of dealing with the coronary anastomoses. By excising "coronary buttons," the aortic-coronary anastomosis was facilitated, and this approach became a standard operative technique. Without the need for aortic wrapping, an additional hurdle was overcome and the potential for additional complications was avoided.

This era of innovation saw a dramatic decrease in early complications and the development of an arsenal of techniques that allowed the surgeon to approach any particular anatomy with the confidence that it could be successfully repaired. Now, without the same impediments faced by the early surgeons, focus began to shift. The aim was to find what would be the ideal way to provide long-term benefits of operation, allowing surgery to be offered not only as a life-saving operation, but also as a prophylactic means to prevent disaster.

\section{Into the Modern Era: The Trend to Incorporate} Valve-Sparing Techniques

The initial operative techniques developed in the 1960s and modified throughout the following decades are not all that dissimilar from those in practice today. As results became more favorable, and larger study cohorts were established, the surgical approach was able to be refined based on data rather than theory, securing reliable long-term results.

The ability to perform earlier surgery in patients, where the pathologic process had yet to permanently affect the leaflets, was an attractive prospect. This would enable restorative surgery without the inherent drawbacks of valve replacement. A native valve best suits the complex dynamic anatomy of the valve apparatus and enhances the maintenance of left ventricular function and coronary flow under a range of loading conditions. Not only is the possibility of a valve-conserving surgery ideal for hemodynamic factors, but it also eliminates the complications intrinsic to valve replacement surgery (e.g., anticoagulation and degeneration of bioprostheses). Despite the attractiveness of such a procedure, the long-term results remained largely unknown until the late 1990s.

Until large enough cohorts of patients had been compiled and meta-analyses completed, there remained two competing methods of sparing the aortic valve. The first was developed by Sir Magdi Yacoub, and had been used in his practice since 1979 [24,25]. The procedure, which he designed, later became referred to as a remodeling technique. The functional focus was to preserve the native valve, while recreating the aortic sinuses believed to be important in efficient flow of blood from the aortic root into the coronary lumen and relief of stress on the native valve leaflets (Fig. 3). Yacoub achieved this goal by fashioning a scalloped Dacron ${ }^{\circledast}$ graft such that three tongues extended to replace the intrinsic sinuses. Interposed between these three extensions, native tissue was left intact at the attachment of the cusps. Once the graft was attached, the coronary arteries would be mobilized and anastomosed to the neosynthetic aorta. During its development, this procedure seemed promising and, in fact, was adopted by many centers. However, as more evidence accrued, it appeared that this approach left patients susceptible to echocardiographically and clinically significant aortic insufficiency [26-28]. This can be attributed to the lack of stabilization of the aortic annulus. Without fixing the diameter of the aortic annulus, no protection from future dilation and alteration of root geometry is provided. This is especially critical for patients with Marfan syndrome and other connective tissue disorders. Additionally, since aortic tissue was left behind in order to accommodate the suture line, this tissue could continue to become aneurysmal as it was continually exposed to aortic pressures.

In the late 1980s, Tirone David and his colleagues at the University of Toronto developed an alternative 


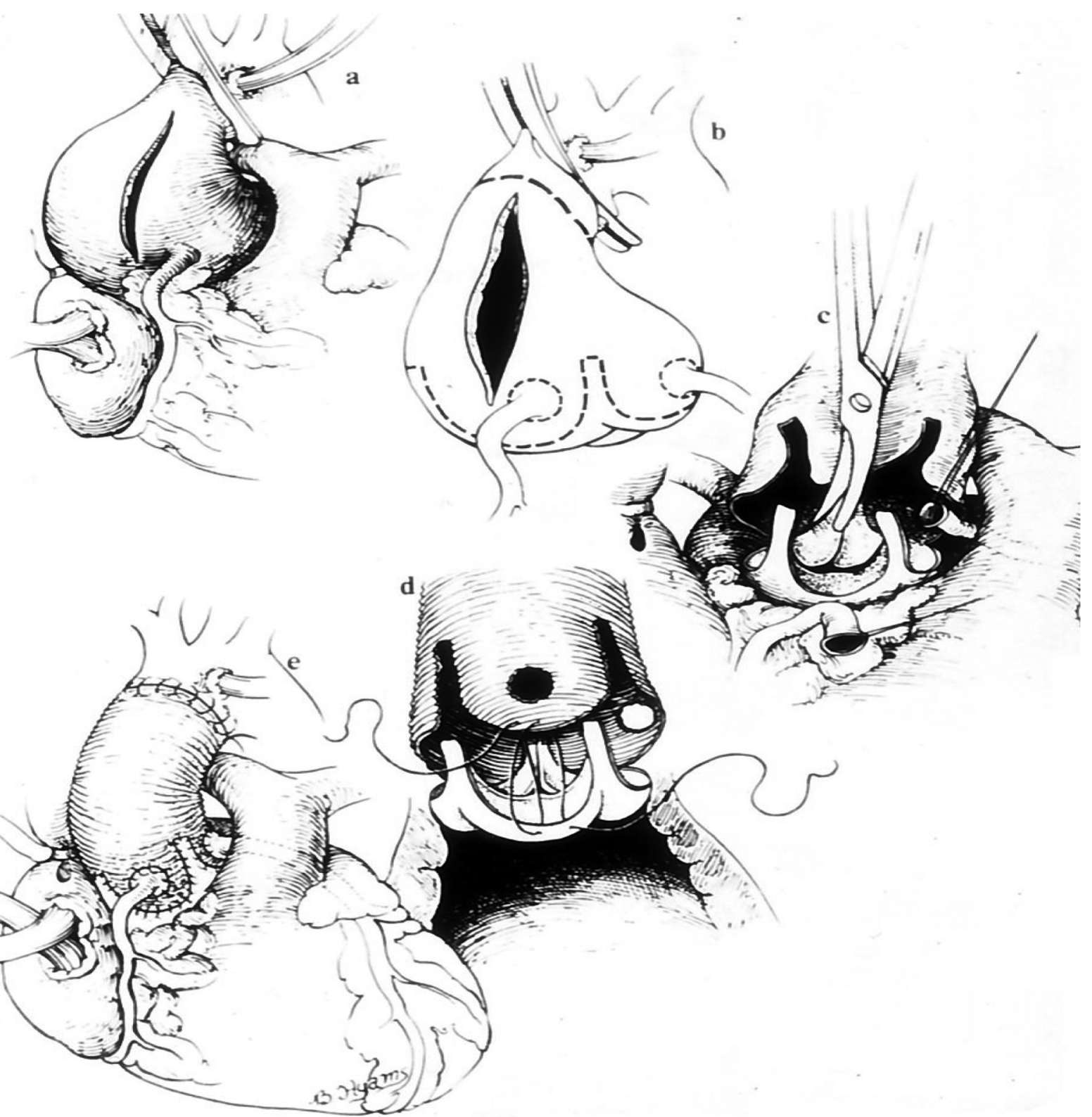

Figure 3. Valve-sparing procedure as done by Yacoub. Figure reprinted with permission from Yacoub et al. [25].

class of valve-sparing procedures [29]. Their procedure went through numerous iterations and variations, but classically the technique became referred to as reimplantation [30,31]. This approach had the benefit of stabilizing the aortic annulus by sewing the native valve directly into a Dacron ${ }^{\circledR}$ graft of a fixed circumference (Fig. 4). This provided greater protection from late complications than did Yacoub's remodeling, but it did not recreate the geometry of the sinuses. The significance of this deficit has yet to prove itself clinically, but theoretically, and experimentally, the lack of sinuses places undue stress on the valvular apparatus. An ideal approach would incorporate the annular stabilizing properties of reimplantation while mimicking the native geometry of the sinuses of Valsalva.

Although Tirone David was instrumental in the development of the reimplantation technique, it is not to say that his group exclusively used this procedure. In their 2006 paper that compared the results of the two techniques, they stated that "no particular criterion was used to select the type of aortic valve sparing" procedure [32], p.348. Throughout the years they 


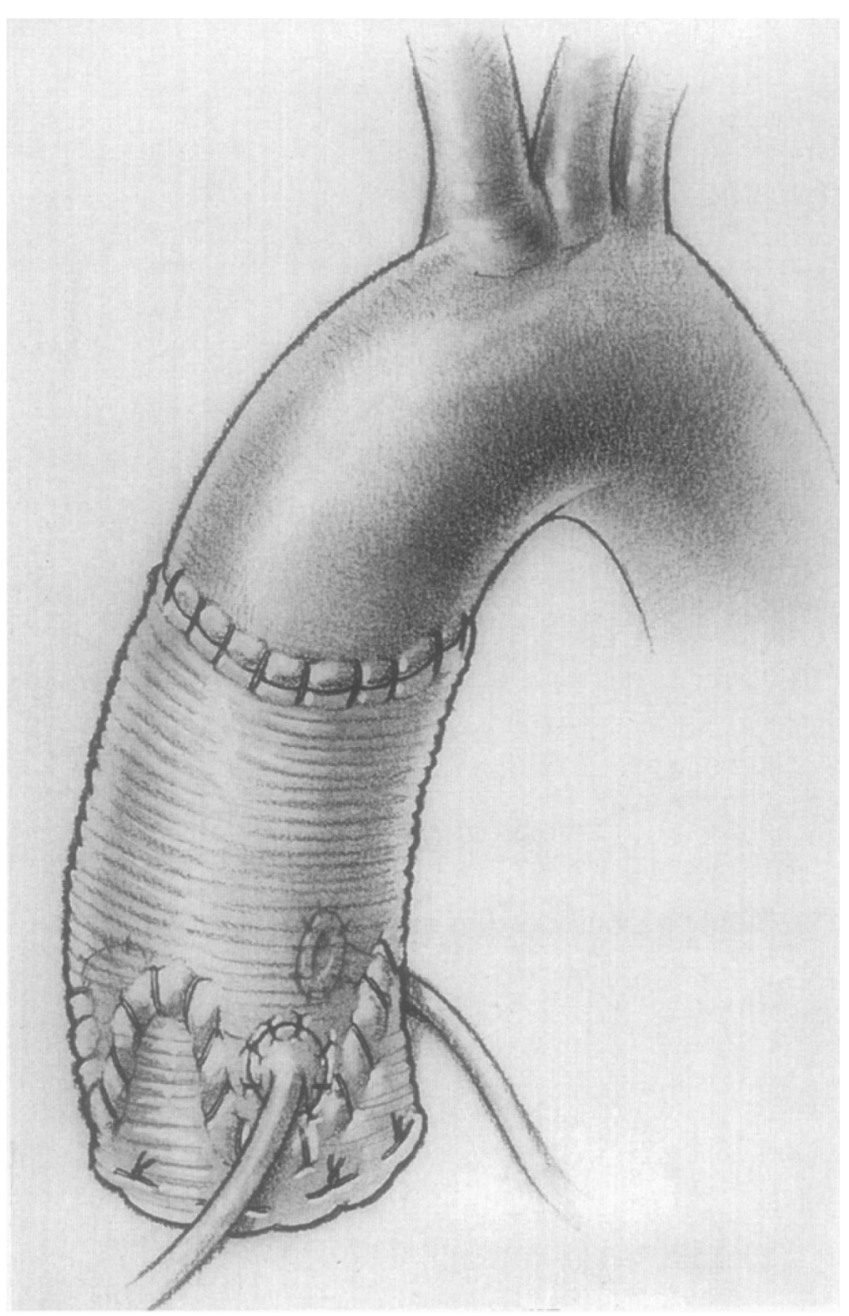

Figure 4. Valve-sparing procedure as done by David. Figure reprinted with permission from David et al. [35].

refined their technique, adding numerous modifications. A classification schema beyond simply calling a procedure reimplantation versus remodeling was needed, and despite the objections of David, Miller popularized the David-I through David-V classification (Table 1) [1]. He labeled David's classic reimplantation procedure using a cylindrical tube graft as David-I, while Yacoub's classic remodeling procedure was identified as a David-II. In this system, David-III referred to a remodeling variation where a synthetic strip is placed over the fibrous portion of the left ventricular outflow tract, achieving a narrowing and reinforcing annulopasty. The final two methods identified are variations on reimplantation. David-IV refers to the technique of using a graft $4 \mathrm{~mm}$ larger than the annulus to allow for plication, and David-V employs an
Table 1. David Classification by Miller for Valve-Sparing Aortic Root Replacement Surgery

\begin{tabular}{|c|c|c|}
\hline David & Type & Modification \\
\hline I & Reimplantation & Classic \\
\hline II & Remodeling & Classic \\
\hline III & Remodeling & $\begin{array}{l}\text { Plus external synthetic strip over } \\
\text { fibrous portion of left ventricular } \\
\text { outflow }\end{array}$ \\
\hline IV & Reimplantation & $\begin{array}{l}\text { Plus plication of graft }(\mathrm{d}+4 \mathrm{~mm}) \\
\text { at sinotubular junction }\end{array}$ \\
\hline V & Reimplantation & $\begin{array}{l}\text { Plus plication of graft ( } d+6-8 \\
\text { mm) at both sinotubular junction } \\
\text { and basal ring to create } \\
\text { pseudosinuses }\end{array}$ \\
\hline
\end{tabular}

d, diameter of aortic annulus.

even larger graft (6-8 $\mathrm{mm}$ larger than the diameter) in order to facilitate the creation of pseudosinuses. Thus, David-I, -IV, and -V are variations on reimplantation, whereas David-II and -III are variations on the remodeling technique originally devised by Yacoub.

In the late 1990s through the present day, attention shifted to focus on the finest details in technique, such as cusp reinforcement, graft sizing to allow for billowing, and plication as a means to recreate sinuses. Dr. Cameron and the group at Johns Hopkins have published some of the largest series on elective repair of patients with connective tissue disorders in need of aortic root surgery [33]. Although a "classic" Bentall (i.e., composite valve-graft replacement) remains the gold standard in their practice, over the years they have introduced valve-sparing procedures when possible. Their initial valve-sparing approach focused on preservation of sinuses with a remodeling procedure, but it soon became apparent that recurrent aortic insufficiency and annular dilation occurred in a significant number of patients soon after their initial procedure. At their center, as these results began to bear out, they transitioned to the reimplantation technique. This transition coincided with the newly approved De Paulis Valsalva graft, and in May of 2002, this combination became the exclusive procedure for valve-sparing operations at Johns Hopkins [34]. Reimplantation with the Valsalva graft has demonstrated promising results and provides both annulus stabilization and aortic sinuses, supplanting either of the classic valve-sparing techniques. 


\section{Conclusion}

In the fifty-eight years since De Bakey and Cooley first replaced an ascending aneurysm with the aid of cardiopulmonary bypass, a number of surgeons devised innovative steps to improve patient outcomes. From the creation of the first useable aortic valve replacement to the valve-sparing techniques described by David and subsequent modifications, surgeons can now treat aortic root pathology without removing a patient's native aortic valve, which greatly improves quality of life. The design of the De Paulis Valsalva graft is another great addition to the surgeon's arsenal and reinforces the need to continue analyzing and improving surgical techniques based on the dynamic physiologic environment of the aortic root. While it is common to hear surgeons refer to aortic root replacements as a "Bentall", the procedures currently employed have undergone an evolution, enough so that what is done now does not resemble the aortic inclusion and side-to-side coronary anastomosis technique. Bentall and DeBono rightfully deserve credit for popularizing the root replacement approach, but others have contributed substantially as well.

\section{Conflict of Interest}

The authors have no conflict of interest relevant to this publication.

Comment on this Article or Ask a Question

\section{References}

1. Miller DC. Valve-sparing aortic root replacement in patients with the Marfan syndrome. J Thorac Cardiovasc Surg. 2003;125:773-778. 10.1067/mtc.2003.162

2. Cheng A, Dagum P, Miller DC. Aortic root dynamics and surgery: from craft to science. Philos Trans R Soc Lond B Biol Sci. 2007;362: 1407-1419. 10.1098/rstb.2007.2124

3. Cooley DA, De Bakey ME. Resection of entire ascending aorta in fusiform aneurysm using cardiac bypass. JAMA. 1956;162:1158-1159. 10.1001/jama.1956.72970290003013a

4. Beckwith J, Muller WH Jr, Warren WD. Problems in the surgical management of acute dissecting aneurysm of the aorta. Ann Surg. $1956 ; 144: 530-548.10 .1097 / 00000658$ 195610000-00003

5. Starr A, Edwards ML, McCord CW, Griswold HE. Aortic replacement: clinical experience with a semirigid ball-valve prosthesis. Circulation. 1963;27:779-783. 10.1161/01.CIR.27. 4.779

6. Herr RH, Starr A, Pierie WR, Wood JA, Bigelow JC. Aortic valve replacement: a review of six years' experience with the ball-valve prosthesis. Ann Thorac Surg. 1968;6:199218. 10.1016/S0003-4975(10)66015-8

7. Bahnson HT, Spencer FC. Excision of aneurysm of the ascending aorta with prosthetic replacement during cardiopulmonary bypass. Ann Surg. 1960;151:879-890. 10.1097/ 00000658-196006000-00011

8. Spiekerman RE, McGoon DC. Aneurysm of the ascending aorta with obstruction of the superior vena cava: report of case with resection using extracorporeal circulation. Dis Chest. 1960;37:675-679. 10.1378/chest.37.6. 675
9. Gaal PG, Maloney JV Jr. Resection and graft replacement of an aneurysm of the ascending thoracic aorta with simultaneous repair of aortic valvular insufficiency. Calif Med. 1963;99:117-120.

10. Garamella JJ, Andersen JG, Oropeza R, Veloso A, Naidu R. The surgical treatment of aortic insufficiency by conversion of the tricuspid aortic valve to a bicuspid valve; chronic experimental studies. J Thorac Surg. 1959;37:177-183.

11. Muller WH Jr, Warren WD, Dammann JF Jr, Beckwith JR, Wood JE Jr. Surgical relief of aortic insufficiency by direct operation on the aortic valve. Circulation. 1960;21:587597. 10.1161/01.CIR.21.4.587

12. Wheat MW Jr, Wilson JR, Bartley TD. Successful replacement of the entire ascending aorta and aortic valve. JAMA. 1964;188:717719. 10.1001/jama.1964.03060340015004

13. Cooley DA, Bloodwell RD, Beall AC Jr, Hallman GL, De Bakey ME. Surgical management of aneurysms of the ascending aorta. Including those associated with aortic valvular incompetence. Surg Clin North Am. 1966;46: 1033-1044.

14. Bentall $H$, De Bono A. A technique for complete replacement of the ascending aorta. Thorax. 1968;23:338-339. 10.1136/thx.23.4. 338

15. Blanco G, Adam A, Carlo V. A controlled surgical approach to annulo-aortic ectasia. Ann Surg. 1976;183:174-178. 10.1097/ 00000658-197602000-00015

16. Zubiate P, Kay JH. Surgical treatment of aneurysm of the ascending aorta with aortic insufficiency and marked displacement of the coronary ostia. J Thorac Cardiovasc Surg. 1976;71:415-421.
17. Cabrol C, Gandjbakhch I, Cham B. [Aneurysms of the ascending aorta; total replacement with reimplantation of the coronary arteries (author's transl)]. Nouv Presse Med. 1978;7:363-365.

18. Piehler JM, Pluth JR. Replacement of the ascending aorta and aortic valve with a composite graft in patients with nondisplaced coronary ostia. Ann Thorac Surg. 1982;33: 406-409. 10.1016/S0003-4975(10)63239-0

19. Cabrol C, Pavie A, Mesnildrey P, Gandjbakhch I, Laughlin L, Bors V, et al. Long-term results with total replacement of the ascending aorta and reimplantation of the coronary arteries. J Thorac Cardiovasc Surg. 1986;91: 17-25.

20. Aoyagi S, Kosuga K, Akashi H, Oryoji A, Oishi $\mathrm{K}$. Aortic root replacement with a composite graft: results of 69 operations in 66 patients. Ann Thorac Surg. 1994;58:1469-1475. 10. 1016/0003-4975(94)91937-2

21. Kouchoukos NT, Wareing TH, Murphy SF, Perrillo JB. Sixteen-year experience with aortic root replacement. Results of 172 operations. Ann Surg. 1991;214:308-318. 10.1097/ 00000658-199109000-00013

22. Sakano Y, Misawa Y, Kaminishi Y, Fuse K. Aorto-right atrium fistula caused by detachment after Bentall's operation: report of a case. Surg Today. 2007;37:234-236. 10.1007/ s00595-006-3355-x

23. Mayer JE Jr, Lindsay WG, Wang $Y$, Jorgensen CR, Nicoloff DM. Composite replacement of the aortic valve and ascending aorta. J Thorac Cardiovasc Surg. 1978;76:816-823.

24. Yacoub M. Valve-conserving operation for aortic root aneurysm or dissection. Oper Tech Card Thorac Surg. 1996;1:57-67. 10. 1016/S1085-5637(07)70081-5 
25. Yacoub MH, Gehle $P$, Chandrasekaran V, Birks EJ, Child A, Radley-Smith R. Late results of a valve-preserving operation in patients with aneurysms of the ascending aorta and root. J Thorac Cardiovasc Surg. 1998;115: 1080-1090. 10.1016/S0022-5223(98)70408-8

26. Benedetto U, Melina G, Takkenberg JJ, Roscitano A, Angeloni E, Sinatra R. Surgical management of aortic root disease in Marfan syndrome: a systematic review and metaanalysis. Heart. 2011;97:955-958.10.1136/hrt. 2010.210286

27. Liu L, Wang W, Wang X, Tian C, Meng YH, Chang $Q$. Reimplantation versus remodeling: a meta-analysis. J Card Surg. 2011;26: 82-87. 10.1111/j.1540-8191.2010.01171.x

28. Rahnavardi M, Yan TD, Bannon PG, Wilson MK. Aortic valve-sparing operations in aortic root aneurysms: remodeling or reimplantation? Interact Cardiovasc Thorac Surg. 2011; 13:189-197. 10.1510/icvts.2011.267401
29. David TE. Remodeling the aortic root and preservation of the native aortic valve. Oper Tech Card Thorac Surg. 1996;1:44-56. 10. 1016/S1085-5637(07)70080-3

30. David TE, Armstrong S, Ivanov J, Feindel CM, Omran A, Webb G. Results of aortic valvesparing operations. J Thorac Cardiovasc Surg. 2001;122:39-46. 10.1067/mtc.2001. 112935

31. Fazel SS, David TE. Aortic valve-sparing operations for aortic root and ascending aortic aneurysms. Curr Opin Cardiol. 2007;22:497503. 10.1097/HCO.0b013e3282efa0f4

32. David TE, Feindel CM, Webb GD, Colman JM, Armstrong S, Maganti M. Long-term results of aortic valve-sparing operations for aortic root aneurysm. J Thorac Cardiovasc Surg. 2006;132: 347-354. 10.1016/j.jtcvs.2006.03.053

33. Cameron DE, Alejo DE, Patel ND, Nwakanma LU, Weiss ES, Vricella LA, et al. Aortic root replacement in 372 Marfan patients: evolution of operative repair over 30 years. Ann
Thorac Surg. 2009;87:1344-1349. 10.1016/j. athoracsur.2009.01.073

34. Patel ND, Williams JA, Barreiro CJ, Bethea BT, Fitton TP, Dietz HC, et al. Valve-sparing aortic root replacement: early experience with the De Paulis Valsalva graft in 51 patients. Ann Thorac Surg. 2006;82:548-553. 10.1016/ j.athoracsur.2006.03.073

35. David TE, Feindel CM, Bos J. Repair of the aortic valve in patients with aortic insufficiency and aortic root aneurysm. J Thorac Cardiovasc Surg. 1995;109:345-351. 10.1016/ S0022-5223(95)70396-9

Cite this article as: Maddalo S, Beller J, DeAnda A. A Bentall is Not a Bentall is Not a Bentall: The Evolution of Aortic Root Surgery. Aorta 2014;2(5):169-178. DOI: http:// dx.doi.org/10.12945/j.aorta.2014.14-021 